\title{
ZARAGOZA VIRTUAL: LA TRANSFORMACIÓN DE UNA CIUDAD
}

\author{
José Daniel Gómez de Segura, Rosa Peral, Diego Sagasti, Sara Sillaurren \\ División de Realidad Virtual \\ European Virtual Engineering
}

Av. de los Huetos 79, Edificio Azucarera

01010 Vitoria, SPAIN

Remisión artículo: 24-4-2007

Palabras Clave: maqueta virtual, urbanismo, comunicación, tiempo real, marketing, comunicación, planificación urbana.

Resumen: Zaragoza se encuentra inmersa en un proceso de transformación sin precedentes en la historia de la ciudad. La llegada del AVE, la Expo 2008 , la construcción de la Ecociudad Valdespartera, el plan de barrios y un caudal de proyectos urbanísticos y arquitectónicos van a cambiar la fisonomía y el funcionamiento de la ciudad tal y como la conocemos actualmente.

La maqueta virtual de Zaragoza que desarrolla EUVE constituye un soporte valiosísimo para la comunicación de todos estos proyectos. Permite al ciudadano de la calle comprender el presente, y conocer el futuro de su ciudad. Por otro lado supone un tremendo reto tecnológico si tenemos en cuenta que la maqueta se mueve en tiempo real: Zaragoza es uno de los municipios más dilatados de la península en cuanto a su dimensión geográfica. Este artículo describe el proceso que se ha llevado a cabo para la construcción del modelo tridimensional de la ciudad con vistas a su visualización interactiva.

\section{Introducción}

Uno de los problemas con el que se enfrentan las administraciones locales es el de la comunicación de los proyectos arquitectónicos y urbanísticos que se van a realizar en una ciudad. En el caso de Zaragoza, en el plazo de dos a cinco años, numerosas intervenciones van a ver la luz: la EXPO 2008, el nuevo barrio del AVE, el soterramiento y modernización de la línea de cercanías, el plan de riberas, el desarrollo de la Ecociudad de Valdespartera, el plan de barrios...

Pero todos estos proyectos conllevan la realización de obras, cambios en el tráfico y adecuación de servicios a la nueva ordenación de Zaragoza. Esto hace necesaria la realización de una comunicación efectiva de las actuaciones que se van a llevar a cabo para que los ciudadanos conozcan la importancia de cada una de las obras, su dimensión y las ventajas que supondrá su realización.

Por otro lado, los proyectos involucran y dependen de distintas instituciones y empresas que tienen intereses diversos y objetivos compartidos. La cantidad de información que se va a generar es ingente, y es imprescindible contar con una herramienta que permita aglutinar todos estos datos de cara a su presentación pública.

La realidad virtual es una tecnología utilizada ampliamente para la visualización de proyectos de arquitectura, urbanismo y obra civil. Las posibilidades de interacción con el modelo tridimensional de una ciudad, permiten presentar y analizar más fácilmente los cambios futuros o la realidad presente. Por otro lado, el desarrollo del hardware, ordenadores y tarjetas gráficas, generalmente propiciado por la explosión de la industria de los videojuegos, 
proporciona mayores capacidades de visualización, tanto en cuanto a dimensiones como a la calidad de los modelos representados.

En el caso del proyecto de la maqueta virtual de la ciudad de Zaragoza, no se trata únicamente de representar una realidad compleja y extensa, si no que además hay que visualizar enormes proyectos urbanísticos en distintas áreas de la ciudad.

Si a esto le añadimos que la información de partida de cada uno de esos proyectos es heterogénea en cuanto a su nivel de desarrollo (plan general, avances de proyecto, proyectos constructivos...), el desarrollo de la maqueta con vistas a su visualización pública, se convirtió en un gran reto tecnológico.

Agradecemos desde aquí, a la empresa Zaragoza Alta Velocidad, su confianza en EUVE a la hora de encargarle este proyecto.

\section{Tecnología}

Una maqueta virtual consta de dos componentes independientes pero que a su vez deben estar perfectamente coordinados y adecuados: por un lado un modelo tridimensional de lo que se quiere visualizar, y por otro, un motor $3 \mathrm{D}$ o programa informativo que sea capaz de "moverlo" en tiempo real. El motor 3D es el encargado de generar cada una de las imágenes de nuestro modelo 3D mientras nos vamos desplazando por él, a una velocidad suficiente como para que el usuario no perciba discontinuidades o saltos en el movimiento.

\subsection{Características del motor 3D}

EUVE como centro tecnológico, desarrolla dentro de sus líneas de I+d un motor 3D para la visualización en tiempo real de proyectos de realidad virtual. El motor se ha desarrollado sobre Direct $\mathrm{x}, \mathrm{y}$ en el momento de desarrollo de la maqueta, y con la utilización de una tarjeta gráfica. GeForce 4600 es capaz de mover de una manera fluida 850.000 triángulos. Esto significa que el número total de triángulos de nuestro modelo 3D no podría pasar de esta cifra. Sin embargo, no se puede caracterizar únicamente un motor gráfico en términos de potencia bruta. Entre otros aspectos, se ha cuidado especialmente la optimización de la geometría en la escena, de forma que el número de objetos se encuentre en los límites que marca el hardware. En caso contrario, sería imposible tratar de mostrar escenas tan complejas como una ciudad en 3D. Asimismo, es necesario un manejo avanzado de materiales.

Entre los requerimientos adicionales para la presentación pública del desarrollo de Zaragoza estaba su utilización como elemento aglutinador de otros desarrollos paralelos que se hubieran realizado anteriormente, como videos, infografías, audio o texto, de manera que complementara la información 3D con otros datos multimedia.

El motor 3D de EUVE permite la visualización de distintos tipos de información al seleccionar cualquier elemento 3D de la maqueta.

Para controlar la forma en la que se muestran estos elementos multimedia, se cuenta con un lenguaje integrado de script. Con él, se pueden automatizar acciones dentro del mundo virtual creado, más allá del simple control de reproducción de un video. 


\section{Architecture, City, and Environment
Arquitectura, Ciudad y Entorno}

\section{Antecedentes}

Existen numerosas iniciativas europeas para el desarrollo de "ciudades virtuales". Algunas han sido utilizadas para mostrar eventos deportivos que se van a celebrar en la ciudad, mostrando las infraestructuras previstas: presentación de la candidatura Paris 20121 cuya maqueta para Internet podemos ver en la Fig.1, información sobre los juegos de invierno en Turín 20062 en la que se puede visualizar la posición de los distintos emplazamientos como en la Fig. 2, o la Marathon de Berlin 20053 cuya aplicación puede comprarse en la web site de la empresa y que podemos ver en la Fig. 3.

Otras aplicaciones están destinadas a dar a conocer futuros desarrollos urbanísticos o arquitectónicos, por lo que solo permiten realizar una visita parcial a las zonas afectadas por los proyectos.

Fig. 1. Maqueta virtual de París (Desarrollada por Archivideo)

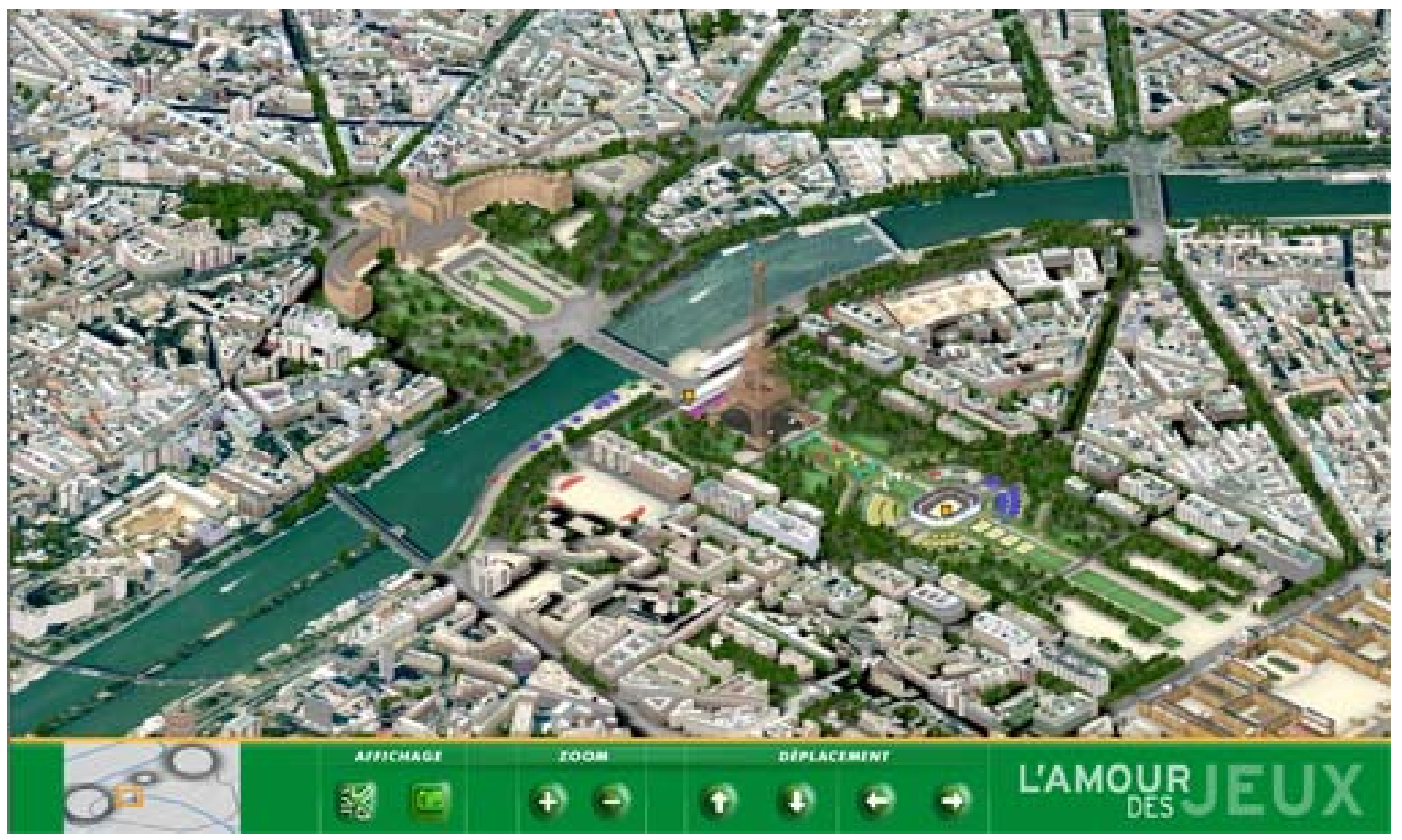

www.archivideo.com

www.ultramundum.org.

www.3dgeo.de 


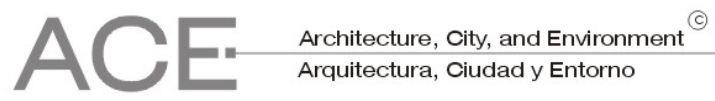

Fig 2. Maqueta virtual de Turín (desarrollado por Ultramundum)

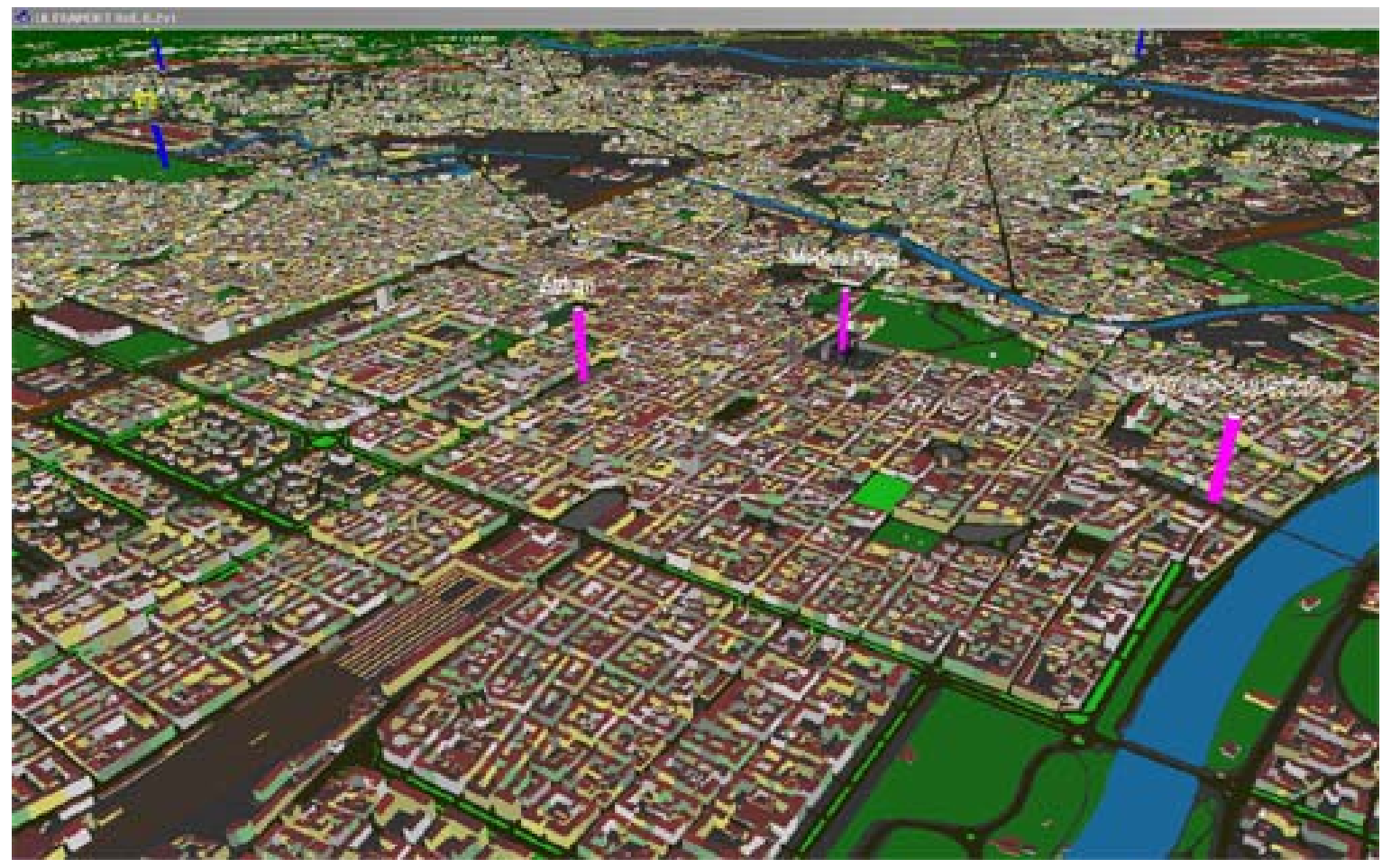

Fig 3. Maqueta virtual de Berlín (Desarrollada por 3DGeo Gmbh)

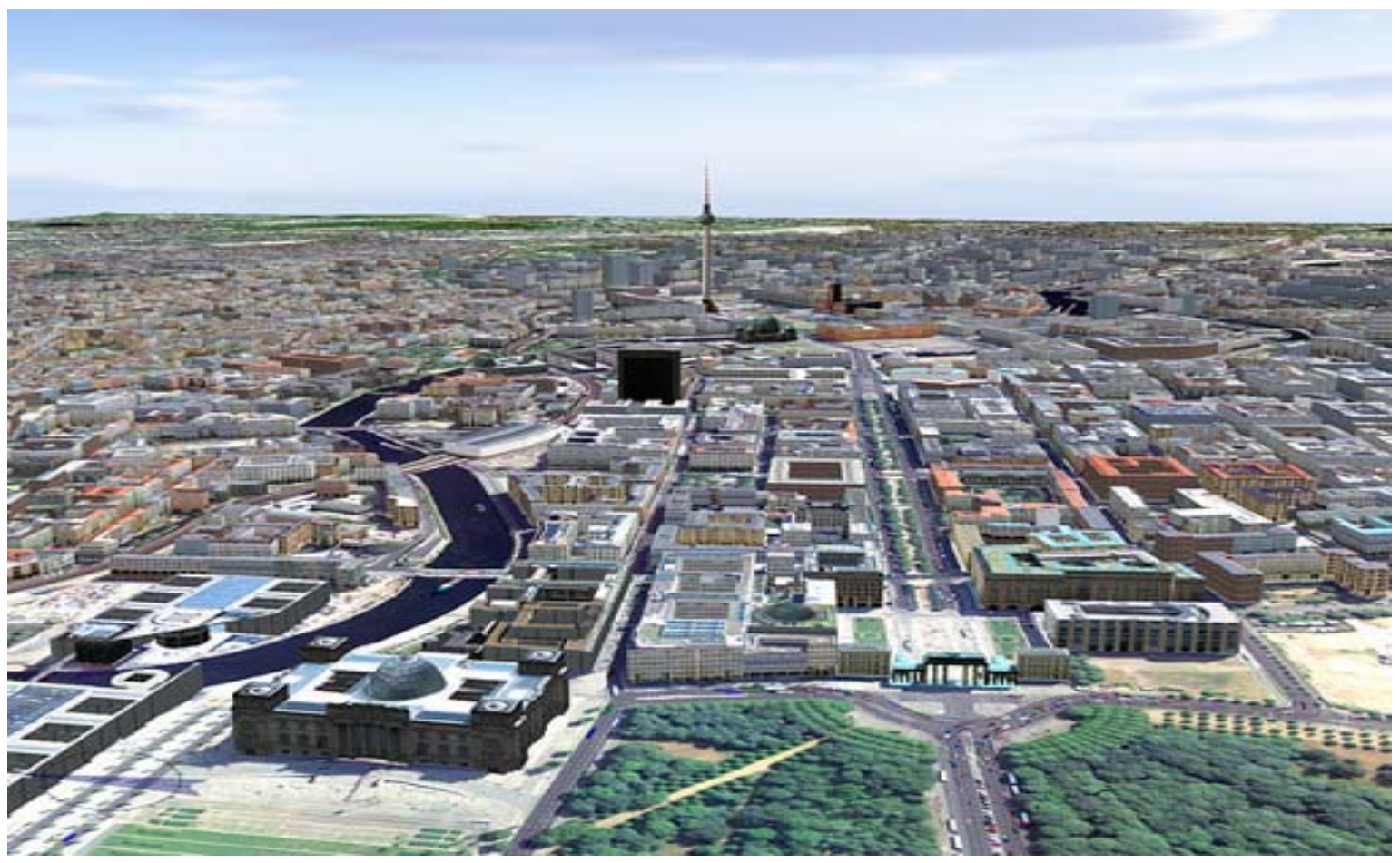


Otro de los usos más habituales de las maquetas virtuales de ciudades es como elemento de marketing, promocional o con fines turísticos, habitualmente desarrolladas para ser visualizadas a través de Internet como las realizadas por la empresa Skyline ${ }^{4}$ y cuya maqueta de París podemos ver en la Fig. 4 o las aplicaciones de la empresa Viewtech ${ }^{5}$.

Fig 4. Maqueta virtual de París (Desarrollada por Skyline)

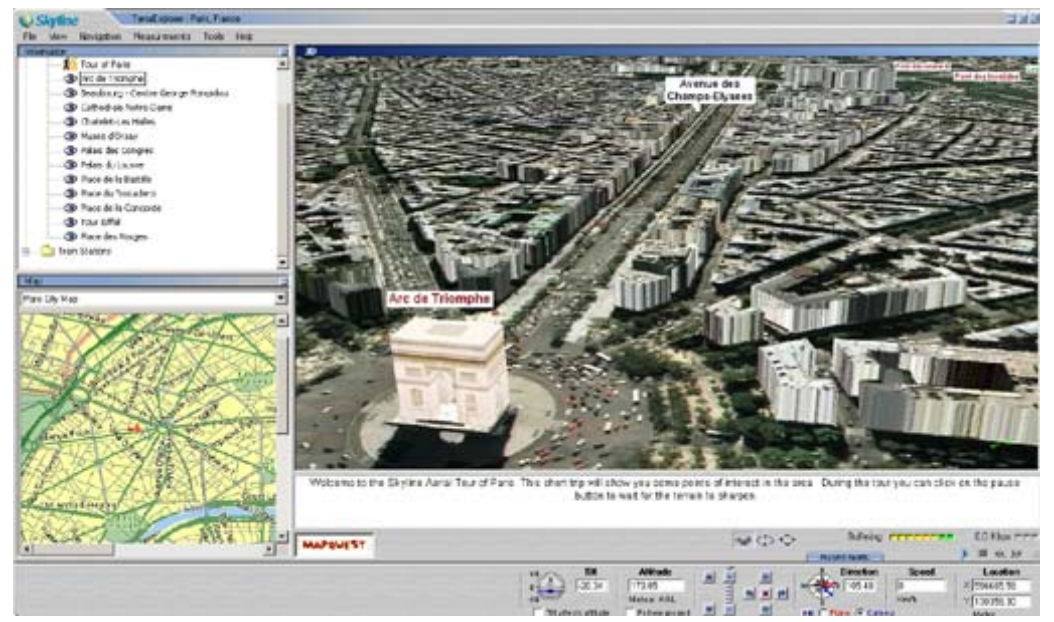

Fig 5. Maqueta virtual de Salzburgo (Desarrollada por Viewtech)

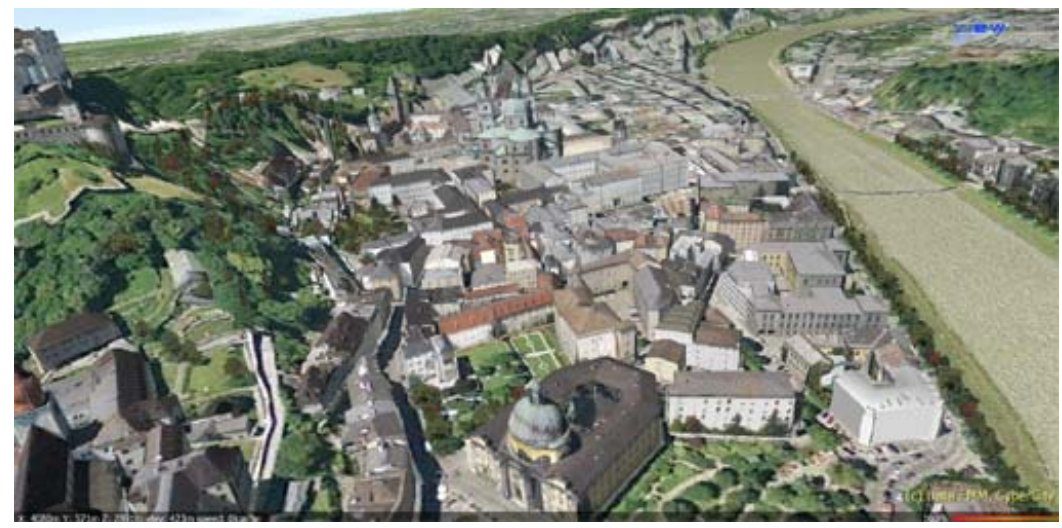

Con este objetivo se está desarrollando uno de los principales proyectos en la actualidad: Google Earth, que pemite recorrer en 3D numerosas ciudades del mundo como se puede ver en la Fig. 6. Hasta ahora los modelos 3D están sin texturizar 6y sólo se pueden visitar algunos edificios o áreas concretas, pero cada vez se va ampliando el número de ciudades disponibles. Para la realización de los modelos se utiliza el software Google Sketchup, que en su última versión permite incoporar modelos $3 d$ totalmente texturizados.

\footnotetext{
${ }^{4}$ www.skylineglobe.com

${ }^{5}$ www. viewtech.ch

${ }^{6}$ En la versión 4 de Google Earth recientemente aparecida, ya es posible incluir texturas y materiales en los modelos 3D. http://earth.google.com/earth4.html
} 
Fig. 6. Maqueta virtual de Boston (Desarrollada por GoogleEarth)

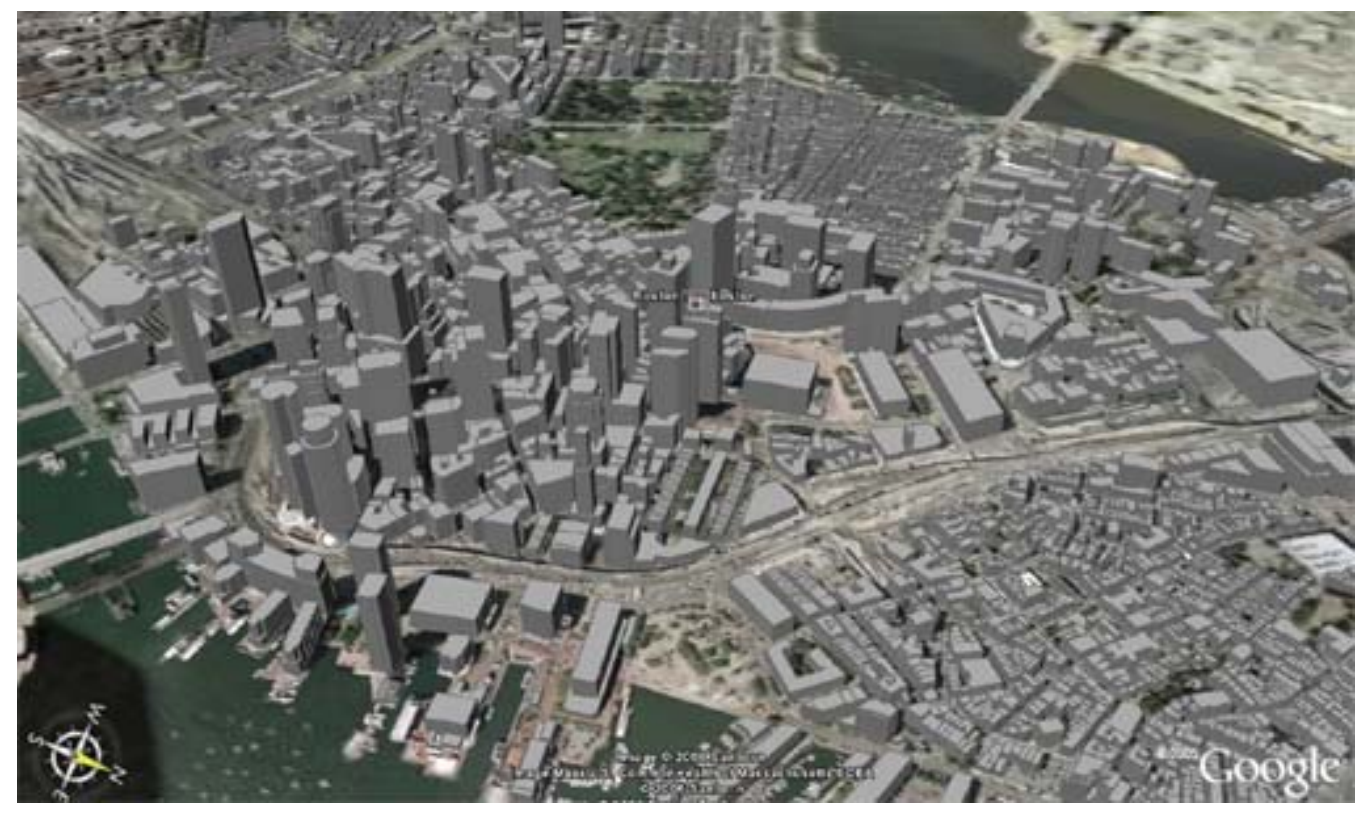

\subsection{Proyectos realizados por EUVE}

En EUVE también se han realizado modelos parciales de ciudades con anterioridad. En el caso de la maqueta virtual del proyecto de ordenación de Castilleja de Guzmán, se realizó un modelo 3D de la ciudad de Sevilla. Este modelo se desarrolló a partir de la cartografía del Ayuntamiento y se usó como referencia visual en la maqueta. En la Fig. 7 se puede observar el modelo tridimensional generado, con el pueblo de Castilleja en primer lugar, en el que el proyecto de ordenación se representa mediante bloques. Al fondo podemos ver Sevilla y en el centro el municipio de Camas.

\section{Fig 7. Maqueta Virtual de Castilleja de Guzmán con Sevilla al fondo}

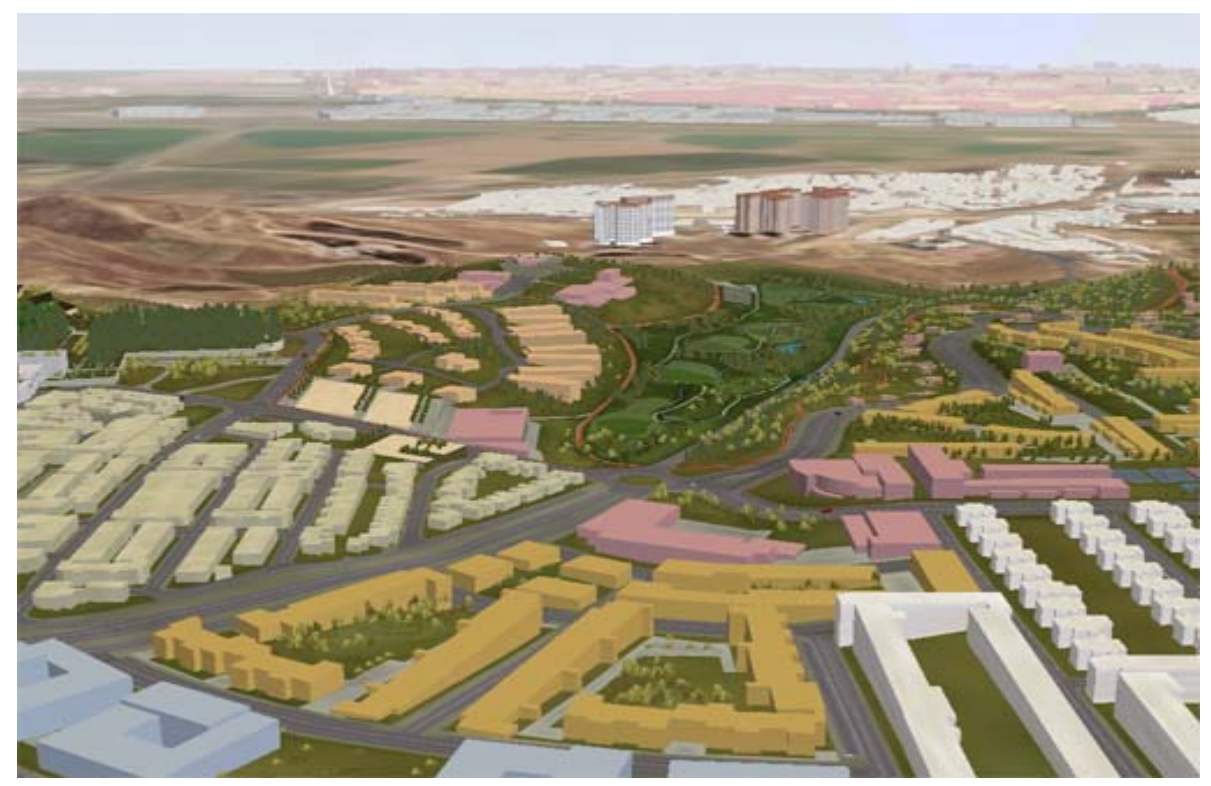


Otros modelos realizados incluyen Bilbao, Vitoria (Lakua) o Barakaldo, con un nivel de detalle dependiente de las necesidades concretas de cada proyecto y del tiempo disponible para su realización.

Fig. 8. Maqueta Virtual de Lakua (Vitoria)

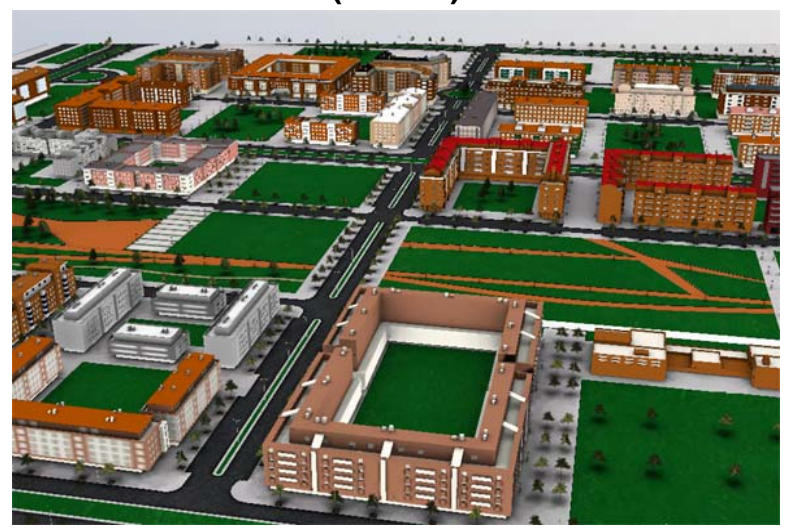

Fig. 9. Maqueta Virtual de Barakaldo

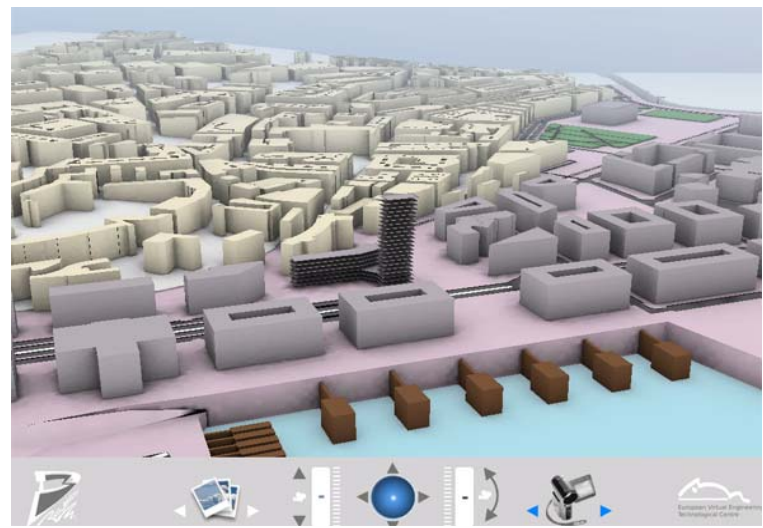

En el área de la construcción, se han desarrollado proyectos complejos tanto en extensión como en la calidad de los proyectos representados: maqueta virtual de la Y Vasca con más de $180 \mathrm{~km}$ de vías representados, o maqueta virtual de la variante sur metropolitana con $36 \mathrm{~km}$ de carretera perfectamente integrados en el terreno del territorio histórico de Bizkaia.

Esta experiencia en el desarrollo de grandes proyectos es lo que nos permitió abordar un proyecto como la maqueta virtual de Zaragoza con garantías de éxito.

\section{La maqueta virtual de Zaragoza}

Uno de los aspectos que tuvimos en cuenta a la hora de plantear cómo debía ser el desarrollo de la maqueta virtual de Zaragoza era tener claro que se trataba precisamente de eso, de una maqueta. No se trataba de realizar un vuelo virtual por un modelo fotorrealista de una ciudad. Un modelo hiperrealista hubiera obligado a fotografiar las fachadas de toda la ciudad lo que hubiera imposibilitado terminar el trabajo a tiempo, debido al ingente trabajo de campo y texturizado que lleva asociado.

Para el modelado de los edificios se partió de los datos cartográficos y el PGOU del Ayuntamiento donde se obtuvo la información relativa a la altura de los edificios. Para los tejados de los edificios se utilizó la ortofoto de la ciudad y se decidió desarrollar un conjunto de texturas para las viviendas, que pudieran utilizarse de manera aleatoria para crear la ilusión de ver la ciudad en 3D. En la Figura 10 se se puede ver una imagen obtenida en las primeras pruebas, en las que únicamente se incluían las fachadas de los bloques de viviendas, mientras que en la Fgura 11, se ha empleado ya la ortofoto en las pruebas de los tejados y el suelo. 


\section{$\begin{array}{ll}\text { Architecture, City, and Environment } & \left({ }_{1}\right. \\ \text { Arquitectura, Ciudad y Entorno }\end{array}$}

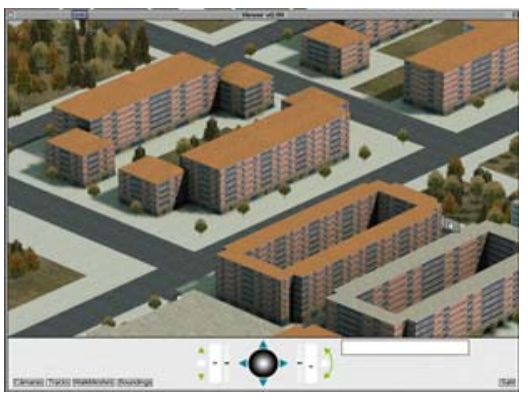

Fig. 10.Prueba con fachadas

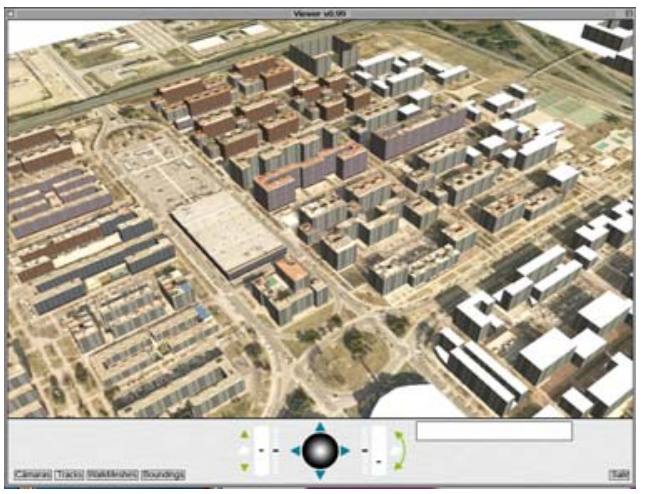

Fig.11. Pruebas finales

Junto a este modelado y texturizado genérico de la ciudad, se han modelado edificios singulares y fácilmente reconocibles que ayudan a visualizar la maqueta, como la Basílica del Pilar, la Aljafería o la estación de Delicias.

Además de los edificios, había que incluir el río Ebro de una manera suficientemente realista ya que algunos de los proyectos mostrados se desarrollan en sus riberas. Después de considerar diferentes soluciones desde el punto de vista del modelado, se optó por desarrollar un módulo para la visualización de agua en el motor 3D.

\subsection{Datos técnicos}

La ortofoto utilizada como base de la maqueta está creada a partir de un mosaico de 4 ortofotos realizadas en el 2006, obteniéndose una foto resultante de $30578 \times 21253$ pixels. Esta ortofoto, se trocea luego en fotos más pequeñas para su optimización a la hora de mover la maqueta en tiempo real.

Adicionalmente, se incorporaron ortofotos que rodeaban a ésta, pero con menor resolución, para conseguir una visualización más realista en los bordes de la maqueta virtual.

Fig. 12. Ortofoto del municipio de Zaragoza utilizada en el proyecto

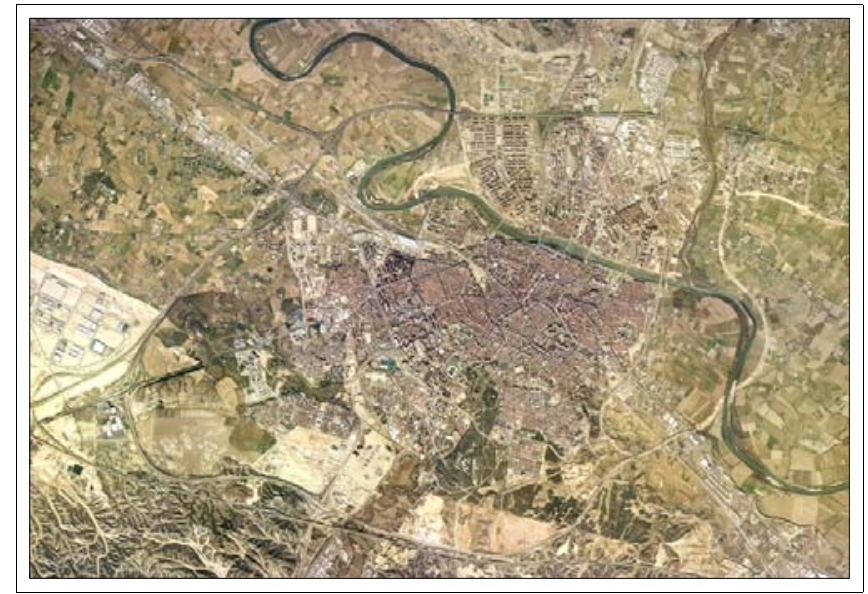


Después de modelar todos los edificios genéricos se han obtenido aproximadamente 6500 objetos, con un total de 120.000 triángulos.

El tamaño total de las texturas utilizadas es de $1,80 \mathrm{~GB}$

\subsection{Proyectos de urbanismo incluidos}

El objetivo del desarrollo de la maqueta virtual de Zaragoza es su utilización como soporte de visualización para proyectos urbanísticos concretos. Los proyectos que están o estarán incluidos cuando finalice el desarrollo son:

- Proyecto de urbanización del barrio del AVE

- Puente del Tercer Milenio

- Estación de Portillo

- Proyecto de urbanización de Portillo

- Nuevas estaciones línea de cercanías

- Ecociudad Valdespartera

- $\quad$ Expo 2008

- Proyecto de márgenes y Riberas del Río Ebro

\subsection{Datos multimedia}

Junto a los modelos 3D de los proyectos anteriormente indicados, desde la maqueta virtual es posible visualizar distintos tipos de información multimedia. El usuario sólo tiene que pinchar sobre los elementos de la maqueta que sean de su interés para ver infografías, videos o textos preparados con anterioridad a la exposición pública de la maqueta o expresamente preparados para ella.

Con el fin de facilitar la visualización de la maqueta, se han incluido además una serie de cámaras predefinidas y unas rutas automáticas, que permiten recorrer de manera sencilla los puntos más interesantes de la maqueta.

\section{Resultado}

El primer hito del proyecto fue la Feria General de Zaragoza celebrada del 1 al 14 de Octubre en Zaragoza. En esta feria, la empresa Zaragoza Alta Velocidad tenía un stand en el que se presentaron las actuaciones que esta empresa va a llevar a cabo en los próximos años en Zaragoza. Para ello se utilizó una pantalla formada por 9 pantallas de 42 pulgadas en la que se podía ver la maqueta ejecutándose de manera desatendida. Con este fin se programaron una serie de rutas automáticas que enlazaban recorridos por la maqueta con vídeos preparados para esta feria, relativos a las cuatro actuaciones principales: barrio del AVE, barrio del Portillo, Red de Cercanías y Puente del Tercer Milenio.

Ademas se realizó una revisión exhaustiva del código del motor 3D que movía toda la maqueta, de manera que ésta pudiera funcionar sin errores durante 10 horas seguidas cada día.

En las siguientes imágenes se pueden ver diversas capturas del modelo 3D obtenido finalmente. 


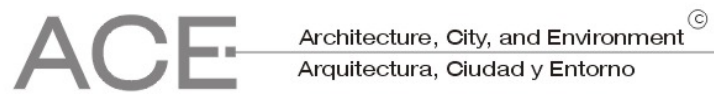

Fig. 13. Utimas pruebas de la maqueta, sin árboles y sin proyectos concretos

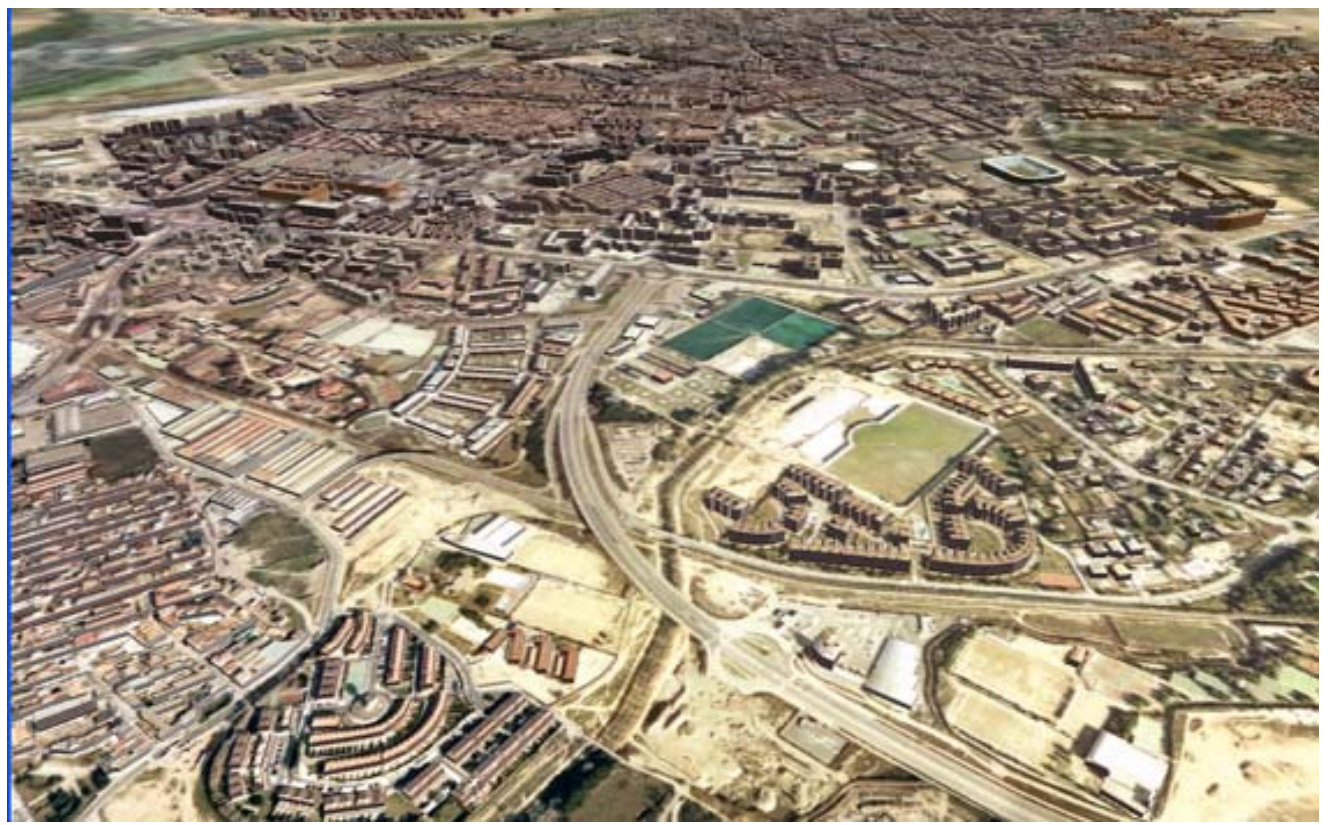

Fig. 14. Utimas pruebas de la maqueta, sin árboles y sin proyectos concretos (Zona de Portillo)

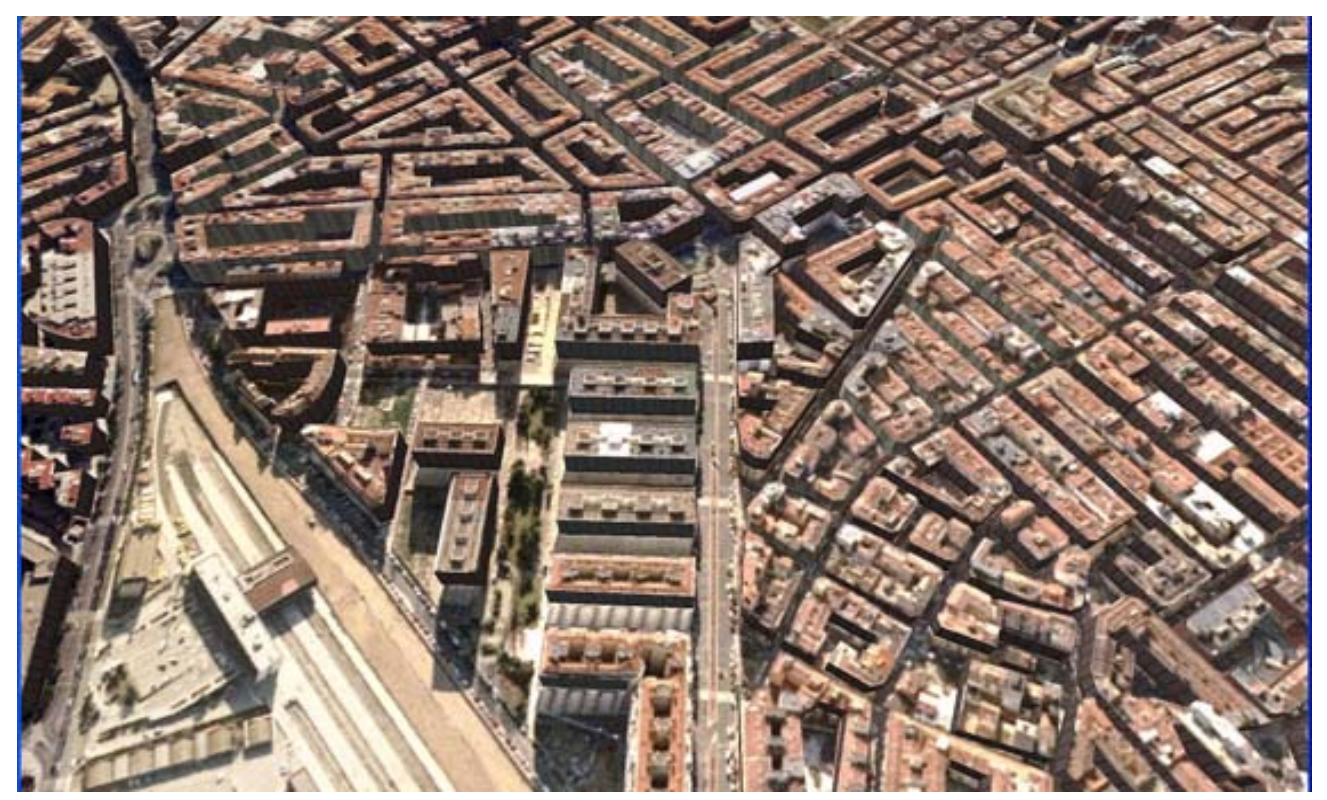

